\title{
PENGUATAN KARAKTER DAN PRESERVASI PENGETAHUAN MELALUI PEMBACAAN PRASASTI: STUDI PEMBACAAN PRASASTI DADIA ARYA DALEM TARUKAN
}

\author{
Luh Putu Sri Ariyani ${ }^{1)}$, Ade Asih Susiari Tantri ${ }^{2)}$ \\ ${ }^{1}$ D3 Perpustakaan, FHIS Universitas Pendidikan Ganesha \\ ${ }^{2}$ Pendidikan Bahasa dan Sastra Indonesia, FBS Universitas Pendidikan Ganesha \\ Email: putu.sri77@gmail.com
}

\begin{abstract}
The purpose of education in Hinduism is to establish an adult human or dewasa (dewasa = human with god character). Education is also an attempt to achieve Catur Purusa Arta (the four goals of human life). Having enough knowledge will help people build good characters. Strengthening the human characters are not only trained in the school but also in the family environment. Balinese tradition in transferring moral messages for the younger generation is very diverse. One of them is through the reading "prasasti" on certain clans in Bali. Prasasti is lontar (palm-leaf manuscript) contained a genealogy or a chronicle of a clan. "Prasasti" is usually read once every 210 days. All members of the clan will gather at the family temple to listen to the messages which inherited by their ancestors. Knowing the chronicle of the family is very important for Balinese in order to increase pride and self-esteem. In this event, youth would learn how important to be good people. At the end of the reading, the elders will give commentary to the text in order to be imitated by future generations. In the context of library science, Balinese are familiar with the information literacy as a means to pass on the knowledge from generation to generation in order to pass on the noble values that have been handed down. This paper tries to explore: (1) why some clans still maintain the tradition of reading "prasasti", while there are clans that did not; and (2) what values are presented at the time of reading "prasasti".
\end{abstract}

Keywords: prasasti, lontar, character strengthening, information literacy

\section{PENDAHULUAN}

Di era globalisasi manusia mengalami proses pendunian karena kemajuan teknologi komunikasi dan informasi maupun teknologi transportasi. Akibatnya, negara-negara di dunia menjadi tanpa batas sehingga terjadi aliran berbagai unsur kebudayaan dari negara-negara maju ke negara-negara berkembang dan melahirkan ideologi global berbentuk konsumersime. Ideologi ini melahirkan masyarakat konsumsi yang memiliki ciri-ciri antara lain, pertama, ukuran kebahagian hidup manusia adalah mengonsumsi barang dan/atau jasa yang sebanyak-banyak. Kedua, pengonsumsian barang dan/atau jasa tidak menekankan 
pada nilai guna, tetapi pada nilai simbolik - prestise atau harga diri - keberadaan saya tercermin dari barang yang saya konsumsi. Ketiga, barang dan/atau jasa yang dikonsumsi didapat lewat pasar - manusia memposisikan pasar tak ubahnya sebagai tempat suci. Keempat, manusia terjebak pada budaya belanja sehingga berlaku slogan - saya berbelanja maka saya ada. Kelima, kemampuan berbelanja terikat pada uang sehingga manusia memuja uang - moneytheism. Keenam, sistem produksi barang tidak lagi hanya memasukkan bahan mentah, uang, tenaga kerja, dan teknologi sebagai faktor produksi, tetapi juga hasrat sehingga melahirkan sistem ekonomi libido - pengguaan hasrat tercermin pada iklan yang selalu menggugah konsumen agar terdorong membeli barang/jasa yang diiklakan (Atmadja, 2010; Atmadja, 2014; Atmadja, Atmadja dan Ariyani, 2016). Dengan adanya kenyataan ini era masyarakat konsumsi - di kalangan orang Hindu di Bali sering pula disebut Zaman Nungkalik - Zaman Berbalik (Zaman Abnormal). Masuknya globalisme menjadikan generasi muda terlena dengan berbagai kenikmatan semu sehingga semakin jauh dari nilai-nilai luhur agama dan budayanya. Generasi muda Bali terkesan semakin individualis dan semakin memuja budaya negeri lain dari pada negerinya sendiri. Melalui pendidikan keluarga, para tetua di Bali berusaha mempertahankan tradisi yang berisi berbagai nilai luhur yang telah dikembangkan oleh para leluhur mereka melalui tulisan yang di atas daun lontar atau sering disebut sebagai prasasti, yang berisikan nasehat para leluhur pada keturunannya. Tradisi membaca prasasti sangat penting guna mempertahankan pola-pola pewarisan pengetahuan dari satu generasi ke generasi berikutnya.

Pendidikan karakter melalui pembacaan prasasti sejalan dengan hakikat pendidikan sebagai proses pembudayaan dan/atau sosialisasi - menjadikan warga masyarakat mewarisi nilai-nilai dan norma-norma agar setiap warganya bisa berinteraksi sosial secara baik dan benar - masyarakat pun menjadi sehat (Integratif). Fungsi Latensi juga diemban oleh agama mengingat "institusi agama relevan karena tekanannnya pada usaha merumuskan nilai-nilai akhir dan meningkatkan serta memperkuat komitmennya terhadap nilai-nilai itu“ (Johnson, 1986: 136). Tulisan ini berusaha mengeksplorasi beberapa hal: (1) mengapa dadia Arya Dalem Tarukan masih mempertahankan tradisi membaca prasasti sementara 
dadia lain tidak lagi mempraktekannya; dan (2) nilai-nilai apa yang ditanamkan dalam proses pembacaan prasasti?

\section{METODE}

Pendekatan yang digunakan adalah penelitian kualitatif yang bertumpu pada paradigma interpretatif dan paradigma teori sosial kritis (Ritzer, 2012). Objek kajiannya adalah nilai karakter yang tercermin dari berbagai prasasti yang dibacakan pada klan-klan yang secara rutin membacakan silsilah keluarga serta bhisama yang diwariskan oleh leluhur kepada seluruh keturunannya. Bhisama diposisikan sebagai teks untuk dibaca secara hermeneutik guna memahami makna denotatif dan konotatifnya (Hoed, 2008; Hardiman, 2015; Norris, 2006; Barthtes, 2007).

Pengungkapan makna ini tidak saja secara emik lewat wawancara mendalam terhadap informan antara lain kelian Dadia, pemangku, pembaca prasasti, agamawan, dan lain-lain, tetapi disertai pula dengan observasi terhadap asal mula dibacakannya "prasasti" kepada seluruh anggota klan. Selain itu juga dilakukan studi dokumen terhadap lontar yang tersedia pada perpustakaan lontar Gedong Kirtya di Singaraja. Pendekatan emik dipadukan dengan etik sehingga terbentuk narasi sarat makna guna menjawab masalah penelitian.

\section{HASIL DAN PEMBAHASAN}

Agama Hindu memiliki dasar-dasar filosofis tentang pendidikan yang komprehensif. Hal ini dapat dicermati dari beberapa gagasan yang tercakup dalam agama Hindu sebagai berikut. Pertama, di dalam diri manusia ada Tuhan dalam bentuk Atman. Kondisi berimplikasi bahwa manusia tidak beragama sejak lahir. Walaupun demikian manusia memiliki potensi sebagai homo religious. Cirinya, antara lain Atman sebagai percikan Brahman (Tuhan) mengakibatkan sejak lahir manusia memiliki benih-benih ketuhanan dalam wujud kesadaran tertinggi yang selalu mengingatkan, mendorong, dan mengajak agar manusia mendekatkan dirinya dengan Tuhan. Potensi ini dihidupkan lewat pengagamaan dalam suatu komunitas yang dilanjutkan dengan pendidikan agama secara khusus dan/atau tindakan-tindakan keberagaan lainnya secara terus-menerus. Misalnya, 
sembahyang, tidak saja manusia memuja Tuhan, tetapi secara latensi berfungsi pendidikan, yakni memperkuat komitmen manusia akan agamanya - agama tidak hanya sebagai identitas diri, tetapi juga sebagai habitus dalam bertindak sehingga manusia ber-Tri Kaya Parisudha dalam kehidupan bermasyarakat.

Kedua, agama Hindu menggariskan bahwa manusia yang ideal adalah manusia berkarakter sebagai dewa (dewata). Citra ini tidak terberi, tapi bisa dibentuk sesuai dengan hakikat manusia sebagai homo educadum-bisa mendidik dan dididik guna mewujudkan manusia yang diidealkan., tujuan hidup manusia dalam agama Hindu adalah mewujudkan Catur Purusartha - Dharma, Artha, Kama, dan Moksha. Artinya, manusia harus berpegang pada kebajikan (asas moralitas $=$ Dharma $)$ dalam mendapatkan uang (Artha) guna memenuhi keinginan (kama). Jika hal ini dilakukan secara konsisten maka peluang manusia untuk mendapatkan kebahagiaan lahir batin baik pada masa kehidupan maupun pascakematian (Moksha) sangat terbuka adanya.

Ketiga, filsof pendidikan Barat acap kali menyatakan bahwa tujuan pendidikan adalah membentuk manusia dewasa. Kata dewasa bermakna manusia memiliki karakter sebagai dewa (dewa + sya = memiliki karakter seperti dewa). Gagasan ini berimplikasi bahwa ciri-ciri manusia berkarakter kedewataan atau manusia dewasa bisa diposisikan sebagai tujuan pendidikan Hindu. Pencapaian ini dilakukan lewat suatu proses sehingga pendidikan dalam perspektif pendidikan Hindu bisa disebut sebagai proses dewaisasi, dewataisasi atau dewasaisasi. Lawan manusia berkarakter kedewataan adalah manusia berkarakter keraksasaan. Hal ini berimplikasi bahwa pendidikan sebagai proses dewataisasi bisa pula disebut sebagai deraksasisasi. Artinya, pendidikan adalah suatu proses mengendalikan atau bahkan melenyapkan sifat-sifat keraksasaan pada manusia agar manusia lebih menonjolkan sifat-sifat kedewataannya dalam kehidupan bermasyarakat.

Keempat, pendidikan sebagai dewaisasi atau deraksasaisasi lewat pendidikan agama Hindu sangat memungkinkan mengingat tidak saja dalam diri manusia terdapat Atman $=$ Brahman yang selalu membisikan hati nurani manusia agar berbuat kebajikan, tetapi juga karena manusia berpotensi berbuat kebajikan. Sebab, secara psikogenetik dalam tubuh manusia terdapat guna sattwa - binihbenih ketubuhan yang mendorong manusia untuk selalu berkomitmen dengan 
kebajikan. Dengan demikian pendidikan dalam perspektif agama Hindu, selain bisa disebut sebagai proses dewataisasi, dewaisasi atau deraksasaisasi, bisa pula disebut sebagai proses sattwa-isasi - menjadikan manusia agar guna sattwa mengendalikan dua guna lainnya, yakni guna rajas dan guna tamas sehingga menusia menjadi insan berkarakter kedewataan (Radhakrishnan, 2009).

Kelima, pendidikan sebagai kegiatan yang sistemik, tidak saja membutuhkan tujuan, tetapi juga guru. Agama Hindu mengenal empat guru sehingga disebut Catur Guru yang terdiri dari guru rupaka, guru pengajian, guru wisesa, dan guru swadiyaya. Dengan mengacu kepada labelnya, yakni guru ( $g u=$ kegelapan/kebodohan $+r u=$ membebaskan, mengantarkan, menjadikan) maka peran guru sebagai tenaga pendidik adalah membebaskan peserta didik dari kebodohan atau kemiskinan budhi agar mencapai tujuan pendidikan, yakni menjadi manusia berkarakter kedewataan/dewasa. Tugas ini sangat berat sehingga tidak mengherankan jika kata guru bisa pula berarti berat (Kasturi, 1999: 166). Dalam konteks Agama Hindu di Bali, pendidikan tidak hanya pada tataran formal. Ada banyak tradisi yang merupakan pendidikan informal di lingkungan keluarga sebagai sarana untuk

\section{Tradisi Membaca Prasasti}

Lontar adalah salah satu media bagi leluhur orang Bali untuk mendidik keturunannya selain dengan cara-cara lisan. Isi lontar sangat beragam mulai prasasti yang berisikan sejarah, silsilah keluarga, seni dan budaya, tradisi, kebiasaan, karya sastra tradisional, seperti cerita rakyat, prosa dan lain sebagainya. Tulisan ini berfokus pada pembacaan prasasti di kabupaten Buleleng yang pada saat tulisan ini dibuat sedang berlangsung pembacaan prasasti milik dadia Arya Dalem Tarukan. Membaca prasasti milik dadia biasanya dilaksanakan pada hari Saraswati, hari di mana Tuhan menurunkan ilmu pengetahuan ke dunia. Pada hari raya Saraswati, semua pustaka diturunkan untuk didoakan dan dibuatkan sesajen berupa banten Saraswati. Hari raya Saraswati diperingati setiap 210 hari, tepatnya hari Sabtu Umanis Watugunung. Adapun ritual penurunan pustaka dari tempatnya diawali dengan upacara Pasupasti berupa pembersihan baik secara fisik maupun spiritual. Menurut Kelian Dadia Arya Dalem Tarukan, I 
Ketut Suka upacara pembacaan "prasasti sekaligus sebagai ajang merawat lontar supaya tetap dalam kondisi baik dan terbaca dengan jelas. Ditambahkan oleh I Ketut Suka bahwasannya kegiatan membaca lontar tidak selalu berjalan dengan mudah dan lancar. Kesalahan kecil saja bisa membuat acara tersebut batal atau gagal. Pengalaman menarik Ketut Suka ketika berlangsungnya upacara penurunan prasasti dari tempat penyimpanan, secara tiba-tiba ahli baca prasasti mendapat pawisik untuk berhenti sejenak. Ketika ditanyakan kenapa berhenti, rupanya beliau mendapat pawisik kalau prasasti yang akan dibaca dikeluarkan dari tempatnya dengan cara terbalik. Para leluhur mengingatkan agar kejadian seperti itu tidak terulang lagi di masa depan.

Setelah dikeluarkan dan dilapalkan mantra-mantra permohonan ijin kepada Dewata, selanjutnya "prasasti” sudah bisa untuk dibacakan. "Prasasti” dibacakan dihadapan seluruh warga dadia. Pembaca "prasasti" terdiri dari 2 (dua) orang yang berbagi peran sebagai pembaca dan peneges (penerjemah). Di bawah ini akan dipaparkan tentang isi prasasti-prasasti pada dadia Arya Dalem Tarukan termasuk bhisama atau nasehat leluhur mereka yang ditujukan bagi para penerusnya.

\section{Bhisama warga Arya Dalem Tarukan}

Pembacaan prasasti diawali dengan pembacaan sejarah keluarga. Bagi masyarakat Bali, mengetahui sejarah keluarga sangat penting karena segala kehidupan masyarakat Bali sangat terikat dengan waktu dan ikatan darah. Pada saat pembacaan sejarah keluarga, aka nada proses penceritaan berbagai pengalaman para leluhur. Umumnya yang diceritakan adalah cerita-cerita yang berhubungan dengan keperkasaan, kehebatan dan prestasi yang pernah diraih. Setelah penceritaan sejarah keluarga/klan, selanjutnya akan dimulai pembacaan prasasti. Setiap prasasti memiliki bhisama yang berisikan tentang hak, kewajiban, larangan dan keharusan dalam menjalani kehidupan. Namun apabila dilanggar dipercaya akan mendatangkan kutukan dan malapetaka. Adapun beberapa bhisama Arya Dalem Tarukan antara lain sebagai berikut.

a. Tidak menerabas hutan dan tidak makan buah jail (buah jawa); hal ini sebagai balas budi karena dulu Ida Dalem Tarukan diselamatkan oleh pohon Jali ketika bersembunyi dari musuh. 
b. Tidak mengurung, membunuh, atau memakan daging burung Puyuh dan Perkutut; sama halnya dengan pohon Jali, buruh perkutut juga menolong Ida dari musuh dengan mengalihkan perhatian musuh sehingga beliau selamat dari kejaran musuh. Untuk itulah keturunan beliau tidak boleh menyakiti burung tersebut.

c. Tidak memakan beras mentah; suatu kejadian di mana putri Ida Dalem Tarukan sakit hingga wafat disebabkan karena memakan beras mentah sehingga hal ini tidak boleh diulangi oleh keturunannya.

d. Tidak menerima sebutan/ ucapan: "cai" dan "cokor I Dewa"; hal ini sebagai tanda bahwasannya semua manusia berhak menerima penghormatan dan tidak boleh merendahkan orang lain.

e. Tidak membuang atau menyia-nyiakan makanan, minuman, dan uang; bhisama ini bertujuan agar keturunan beliau menghargai segala pemberian dewata dan bersyukur atas segala pemberianNya. Dengan tidak menyianyiakan makanan, diharapkan keturunannya selalu dalam keadaan berkecukupan.

Dari beberapa Bhisama Ida Arya Dalem Tarukan, terlihat bahwa beliau mengajarkan dan mewajibkan keturunannya untuk selalu ingat akan kebaikan seseorang serta tidak lupa membalas budi kepada siapapun atau apapun yang pernah menyelamatkan hidup mereka. Manusia sebagai makhluk yang mewaktu dan meruang - penentu tindakan manusia - Giddens (2010) dalam teori strukturasinya memasukkan unsur waktu dan ruang sebagai komponen penting bagi tindakan manusia. Agama Hindu amat menghargai waktu dan ruang, tidak saja tercermin dari desa, kala, patra, tetapi terkait pula dengan Tri Samaya trilogi kewaktuan, yakni Attita, Nagata, dan Wartamana. Gagasan ini mencerminkan bahwa manusia berkarakter kedewataan memiliki kewajiban berkreativitas - sesuai dengan hakikat manusia sebagai makluk berbudaya dalam konteks menjawab tuntutan kondisi (patra), tetapi tidak boleh merusak lingkungan (desa) dan harus berpedoman pada sejarah (kala - berdimensi Tri Samaya). Namun secara faktual banyak orang bertindak memposisikan lingkungan alam (desa) sebagai objek hasrat semata - muncul kerusakan lingkungan alam yang parah di berbagai daerah. Begitu pula banyak orang 
mengabaikan kesadaran sejarah (Attita, Nagata, Wartamana) sehingga muncul kejadian yang sama polanya - manusia pun terjerumus ke dalam lubang yang sama untuk kedua kalinya atau bahkan berkali-kali. Gejala ini tentu menyedihkan mengingat sejarah adalah guru bagi kehidupan (Historia Magistra Vitae). Dengan demikian tidak mengherankan jika Soekarno, Presiden RI pertama pernah berucap “Jasmerah - jangan sekali-sekali melupakan sejarah". Memahami kembali bhisama khususnya Ida Arya Dalem Tarukan merupakan upaya untuk tidak mengulangi sejarah yang buruk seperti memakan beras mentah dan selalu mengingat kebaikan yang pernah diberikan seseorang kepadanya.

\section{Membaca "Prasasti" dan Upaya Preservasi Pengetahuan Masa Lampau}

Selain menanamkan karakter kebaikan, pembacaan prasasti merupakan upaya melestarikan berbagai pengetahuan yang menjadi warisan dari para leluhur. Tujuannya tidak lain adalah untuk menjaga agar kehidupan para keturunan Ida Arya Dalem Tarukan tetap baik. Dengan membacakan prasasti di hadapan keturunannya diharapkan karakter memancar dari dalam diri mereka atau teraktualisasi secara mantap. Artinya, nilai-nilai karakter yang diinternalisasi menjadi habitus sehingga seluruh warga dadia mempraktikkan bukan atas tekanan orang lain malainkan atas kesadaran dan kamauan diri sendiri. Berkenaan dengan itu tepat gagasan Raka dalam Atmadja (2016) "Karakter adalah apa yang Anda lakukan ketika tak seorang pun melihat atau memperhatikan Anda". Jadi, seseorang secara otomatis berbuat baik dan benar, bukan karena ingin pamer, tetapi karena kebiasaan.

Nilai-nilai karakter yang dipaparkan pada pembacaan prasasti ini merupakan kegiatan preservasi pengetahuan yang di dalamnya terdapat kegiatan menangkap (capture), transfer dan menyimpan pengetahuan pada tandon pengetahuan. Menangkap pengetahuan merupakan awal dari terciptanya pengetahuan baru dapat dilakukan dengan cara alih pengetahuan dari tacit ke tacit, tacit menjadi eksplisit, eksplisit ke ekslpisit atau eksplisit ke tacit (Nonaka, 1994: 18; Karsono, 2010: p.4). Kegiatan menangkap dan transfer pengetahuan dapat dilakukan dengan dua pendekatan yaitu kodifikasi (codification) yang bertujuan untuk mengalihkan pengetahuan tacit ke dalam bentuk dokumen; dan 
personalisasi (personalisation) yang bertujuan untuk membangun tandon pengetahuan berbasis orang sehingga pengetahuan tacit seseorang dapat dialihkan kepada warga dadia yang lain (Hansen, dkk, 1999: p. 3). Apa yang dikemukakan Hensen, dkk sejalan dengan yang dikemukakan oleh Nonaka (1991) yang menganggap bahwa antara pengetahuan tacit dengan pengetahuan explisit tidak berlawanan atau terpisah satu sama lain, melainkan merupakan satu kesatuan yang saling melengkapi. Apa yang dilakukan oleh warga dadia Arya Dalem Tarukan merupakan proses internalisasi yaitu alih pengetahuan explicit menjadi pengetahuan tacit melalui proses pembelajaran di sanggah gede dengan menjalankan aktivitas penerapan suatu jenis pengetahuan eksplisit (dalam hal ini tersurat pada lontar) secara berulang-ulang.

\section{PENUTUP}

Berdasarkan paparan di atas dapat dikemukakan bahwa pembacaan prasasti yang umumnya tertulis pada lontar dilakukan sebagai upaya leluhur untuk mengingatkan keturunannya melakukan segala perintah dan larangannya. Warga dadia merupakan anak yang merupakan pewaris sekaligus penyelamat orang tua dan para leluhur. Anak yang berkarakter baik, berbakti kepada orang tua dan leluhur serta taat kepada ajaran agama merupakan dambaan semua orang tua. Bagi umat Hindu, hidup adalah sebuah perjalanan yang penuh dengan kejadian penting (tonggak sejarah) yang dapat diidentifikasikan sebagai tangga menuju tahapan perkembangan jasmani dan emosional. Untuk itu preservasi pengetahuan leluhur tetap dilakukan melalui kegiatan membaca prasasti.

\section{DAFTAR PUSTAKA}

Atmadja, N.B. 2010.Ajeg Bali: Gerakan Identitas Kultural dan Globalisasi. Yogyakarta: LKiS.

Atmadja, N.B. 2010.Genealogi Keruntuhan Majapahit: Islamisasi, Toleransi dan Pemertahanan Agama Hindu di Bali. Yogyakarta: Pustaka Pelajar.

Atmadja, N.B. 2010. Pendidikan Karakter Bangsa [Hakikat, Tujuan dan Pendekatan dan Model Pembelajarannya]. Makalah disampaikan dalam seminar yang diselenggarakan oleh PGRI Gianyar. 
Atmadja, N.B. 2010. Pendidikan Karakter Bangsa Perspektif Sosiokultural. Makalah disampaikan dalam seminar yang diselenggarakan oleh Kwartir Pramuka Gianyar.

Atmadja, N.B. 2011. Pelembagaan Toleransi pada SMA Multiagama di Bali Perspektif Pendidikan Kritis. Singaraja: Pascasarjana Undiksha.

Atmadja, N.B. dan A.T. Atmadja. 2009. "Pelampiasan Syahwat Kekuasaan dan Ngutang Gae Ngalih Gae: Pemaknaan Pesta Demokrasi di Bali”. Jurnal Kajian Budaya. Volume 6, Nomor 11. Halaman 45-82.

Atmadja, N.B. dan Anantawikrama Tungga Atmadja. 2011. Filsafat Ilmu Pengetahuan [Teknologi, Kebudayaan, Agama dan Marginalisasi Pengetahuan Tradisional]. Singaraja: Program Pascasarjana Undiksha.

Giddens, A. 2010. Teori Strukturasi Dasar-dasar Pembentukan Struktur Masyarakat. [Penerjemah Maufur dan Daryatno]. Yogyakarta: Pustaka Pelajar.

Hansen, M.T., N. Nohria, and T. Tierny. (1999). What's Your Strategy for Managing Knowledge? Harvard Business Review Retrieved from http://www.itu.dk/ kristianskriver/b9/Whats\%20your\%20strategy\%20for $\% 20$ managing\%20knowledge.pdf on June $1^{\text {st }} 2013$

Karsono, (2010). Preservasi Pengetahuan Nuklir. Makalah disampaikan pada Seminar Nasional VI SDM Teknologi Nuklir di Yogyakarta tanggal 18 November 2010.

Nonaka, Ikujiro. (1991). The knowledge-creating company. Harvard Business Review 96-104. Retrieved from http://home.base.be/vt6195217/The\%20knowledge\%20creating\%20comp any.pdf. on February $14^{\text {th }} 2013$.

Nonaka, Ikujiro. (1994). “A Dynamic Theory of organizational Knowledge Creation",Organization Science, Vol. 5, No. 1; 1994. Retrieved from http://www.jstor.org/discover/10.2307/2635068?uid=3738224\&uid=2\&ui $\mathrm{d}=4 \& \operatorname{sid}=21102376618847$ on February $22^{\text {th }} 2013$. 